\title{
Actual conditions of residents' cooling behaviors related to visual and auditory sensation and estimation of their effect on energy saving in Japan
}

\author{
Makoto FuKUSAKA $^{1)}$ and Naoki MATSUBARA ${ }^{2)}$ \\ 1) Division of Environmental Sciences, Kyoto Pref. Univ., \\ 1-5, Hangi-cho, Shimogamo, Sakyo-ku, Kyoto, 606-8522, Japan, E-mail: makoto.efu@ares.eonet.ne.jp \\ 2) Division of Environmental Sciences, Kyoto Pref. Univ., \\ 1-5, Hangi-cho, Shimogamo, Sakyo-ku, Kyoto, 606-8522, Japan, E-mail: n_mats@kpu.ac.jp \\ Author to whom correspondence should be addressed; E-Mail: n_mats@kpu.ac.jp; \\ Tel.: +81-75-703-5426; Fax: +81-75-703-5426.
}

(received on November 29, 2013, accepted on June 27, 2014)

\begin{abstract}
The article aims to investigate residents' cooling behaviors and to examine the possibilities for reducing thermal discomfort, changing the duration of air-conditioner use, and reducing cooling load through behaviors influencing visual, auditory and other sensation. A questionnaire was administered in Kyoto, Japan during summer 2010. The results indicated that: (a) to cool down, many residents engage in daily cooling behaviors other than using air-conditioners, such as using rugs, sprinkling water, bamboo blinds, and having coolcolored interior elements. In addition, many of these behaviors were negatively correlated with the length of air-conditioner use; (b) cooling behaviors include acts to lower the temperature (e.g., sprinkling water and bamboo blinds) and acts to obtain non-heat-related cooling effects (e.g., using rugs, a cool-colored interior, scents with cooling effects, wind chimes, music with cooling effects); (c) a comparison between the simulated cooling load of four groups (categorized according to the use of bamboo blinds and a cool-colored interior) found that the cooling load of the group using both is about $10 \%$ lower than the group using neither.
\end{abstract}

Keywords: visual and auditory sensation, energy saving, residents' behavior, coolness

\section{Introduction}

According to a life satisfaction survey by the White Paper on National Lifestyle in Japan (Cabinet Office, 2007), the proportion of "satisfied" respondents has decreased from $10.9 \%$ in 1978 to $3.6 \%$ in 2005 . For the question, "which is more important, non-material satisfaction or material satisfaction?" in 1972, "material satisfaction" (40.0\%) was prioritized over "non-material satisfaction" (37.3\%). However, in 2005, "non-material satisfaction" was emphasized $(62.9 \%)$. The rise in living standards indicate that a degree of material wealth has already been achieved, thus, the trend is now to emphasize non-material satisfaction.

On the other hand, as a result of a more convenient and affluent lifestyle, energy consumption, including the use of fossil fuel, has expanded. It is estimated that global energy consumption will almost double by 2030 from that in 1990. In particular, the increase in energy consumption in private households, brought about by the spread of air-conditioners, is significant. To maintain various functions of modern society, reduction of energy-related risk is needed (Agency for Natural Resources and Energy, 2013), and as such, energy use at the household level needs to be tackled.

Human beings have expanded their habitat by acquiring the means to adapt to a diverse climatic environment. Humphreys et al. (1998) show various means for thermal adaptation. One is environment adjustment technology such as architecture and facilities. Another is the ways in which human beings use such hardware, in other words, their behavior to adapt to the environment based on their perception of the life environment. Seligman et al. (1979) and Ouyang et al. (2009) focused on the latter. While these studies highlight the importance of perception in improving residents' behavior and their perception of comfort, they do not focus on the possibility of reducing energy use by improving thermal comfort through the visual and auditory sensation. 
Japanese houses are built to incorporate good air ventilation, and the Japanese have coped with the summer heat and winter cold through various means such as sprinkling water in the morning and at sunset while enjoying the changing seasons. As seen in "Makura no soshi" - a collection of essays in the Heian period-changing seasons and everyday events were admired as being "ito okashi (very moving)." It is arguable that no other nation displays such a deep admiration for nature as the Japanese (Kaneko, 1921). It has also been pointed out that the Japanese perception of heat, cold, and comfort is diverse (Horikoshi, 1993). Japan, as an archipelago, experiences clear seasonal changes, although local variation due to the nature of the land that stretches from north to south is also evident. The Japanese have lead a unique low-carbon life with some adaptation in housing function and everyday life to cope with the summer heat and winter cold. A survey by Matsubara et al. (1993), on air-conditioner use and the adoption of traditional environment adjustment techniques by residents of detached houses in Kyoto, indicated the declining use of traditional environment adjustment techniques. In addition, the thermal environment differs according to lifestyle. Thus, it is necessary to consider lifestyle in space design, which includes daily life, building insulation, and heating methods (AIJ, 2007). The relationship between daily life and the size of living quarters and/or heating has been discussed in the field of architectural planning, while the relationship between the thermal environment and daily life has been examined in the field of architectural environmental engineering (Matsubara et al., 2013).

We constantly evaluate stimuli such as light, heat, sound, and air in our surrounding environment through sensation. Research has been conducted on the influence of psychological effects on the interaction between these sensation and residents' thermal perception and sense of comfort. A series of studies by Horie et al. (1985), Sakurai et al. (1990), and Matsubara et al. (1995) focused on the synthesized evaluation of complex environments through various factors using non-specific scales. These have shown that synthesized evaluation of discomfort in moderate stress regions can be expressed by the addition of discomfort stemming from sound, light, and heat factors. In terms of the effects of colors on thermal perception in the study of synthesized environmental evaluation, Bennett et al. (1972) proposed the hue-heat hypothesis, namely that "human beings feel warm in an environment where red is the main color and cool in an environment where blue is the main color." Fanger et al. (1977) reported that, while there is a significant difference of $0.4^{\circ} \mathrm{C}$ in preferred temperature between the two extreme hues of red and blue, there is no practical implication for this difference. Since then, Ohno et al. (1987) demonstrated the significant effect of colors on thermal perception in the process of shifting from thermally uncomfortable conditions to thermally comfortable conditions. Nagano et al. (1996) showed that environmental factors not thought to be directly relevant influence each environmental factor, and that specific evaluations of environmental factors on several scales influences evaluations specific to other environmental factors. Matsubara et al. (2000) evaluated color conditions closer to everyday life, showing that the reducing effects of psychological load on heat through visual factors are greater with regard to cool colors on the high temperature side and warm colors on the low temperature side. In addition, a linear regression of the relationship between thermal sensation and temperature showed that adding visual and auditory factors decreased the gradient of the regression formula (i.e., the response to thermal environmental factors in relation to the increase in room temperature). This can be explained by the distribution of attention (Matsubara et al., 2007). It is meaningful to explore the possibility of reducing energy consumption by combining different sensation, such as by improving a sense of comfort or reducing the heat and cold. However, preceding studies are based on empirical experiments and little research has been undertaken in someone's home.

In order to address this issue, a questionnaire survey to determine cooling behaviors at home during the summer was administered to a few hundred people. The aim of the study was to ascertain whether psychological effects derived from visual and auditory sensations mediated residents' cooling behaviors. In addition, to elucidate the possibility of reducing cooling load, the study aimed to determine whether the psychological effects of elements influencing sensation also serve to reduce thermal discomfort and influence the duration of air-conditioner use. In this study, "cooling behaviors" include the physical effects on perceived temperature, such as wind speed and changes in wind speed (Saito et al., 1999); behaviors to obtain psychological coolness through visual and auditory sensation that do not influence perceived temperature; and behaviors by residents to change the way they live to improve the overall sense of comfort and reduce "heat" and thermal discomfort.

\section{The cognitive appraisal and coping model}

The authors (2013) conducted research in 11 houses in Kyoto, adding several sensation besides visual and auditory elements to those already studied in previous empirical experiments, and found that residents tolerated heat by using their sensation to actively adapt to the environment, which resulted in overall satisfaction. By using the processes of appraisal and 
residents' coping to the environment, we have also attempted to understand diverse environment adjusting cooling behaviors (behaviors to create the perception of coolness) in situations where acceptable thermal environments differ from house to house in response to summer heat. With regard to residents' adaptation behaviors to the thermal environment, Matsubara et al. $(1999,2013)$ proposed a model suggesting that evaluation of satisfaction or dissatisfaction above thermal sensation and thermal comfort due to the external environment triggers either improving the environment or escaping from it. On the other hand, the authors developed the perceptional appraisal model of stress proposed by Folkman et al. (1988) in their study of 11 houses (Fukusaka et al., 2013), and proposed a perceptual appraisal and coping model based on the idea that differences in environment adjustment behavior stem from the perception and appraisal of a complex environment comprising visual and auditory elements (Figure 1). In other words, a resident perceives the "external environment" and "indoor environment" primarily through stimulation of their visual and auditory sensation. The "indoor environment" includes thermal environment factors, which have been reduced by facilities and different ways of living; visual factors (e.g., the landscape of the neighborhood that can be seen from inside the house); and auditory factors. In the process of "appraisal," the degree of comfort and overall satisfaction with the house is evaluated and the direction of responses based on this is determined.
Every resident's appraisal is biased (because of physical factors, attention, and preferences), thus, there is a large degree of variation in terms of environmental appraisal and the direction of responses. In addition, in some cases, a synthesized perspective guides appraisal, which mobilizes vision and hearing such as what can be seen from the window, birds' singing, and insects' sounds, in addition to the thermal environment. For the next step, "coping," there are variations such as direct responses to the environment (e.g., changing a hot environment by using an air-conditioner or moving to a different place) and indirect responses (e.g., maintaining the physical environment or modifying the interpretation of the situation by shifting the distribution of attention). Consequently, perception and environmental appraisal is reviewed. Here, temporal changes induced by learning are not considered. The above explains the overall daily appraisal of the life environment. It also suggests that the perception of coolness created through various means influences thermal appraisal and coping, as evident when non-thermal visual and auditory elements, such as a cool-colored interior and wind chimes, mitigate thermal discomfort. Through this, one can expect energy conservation and increased overall satisfaction.

\section{Method}

A questionnaire survey was conducted on residents' use of air-conditioners and electric fans during summer, their cooling behaviors, and reasons for these

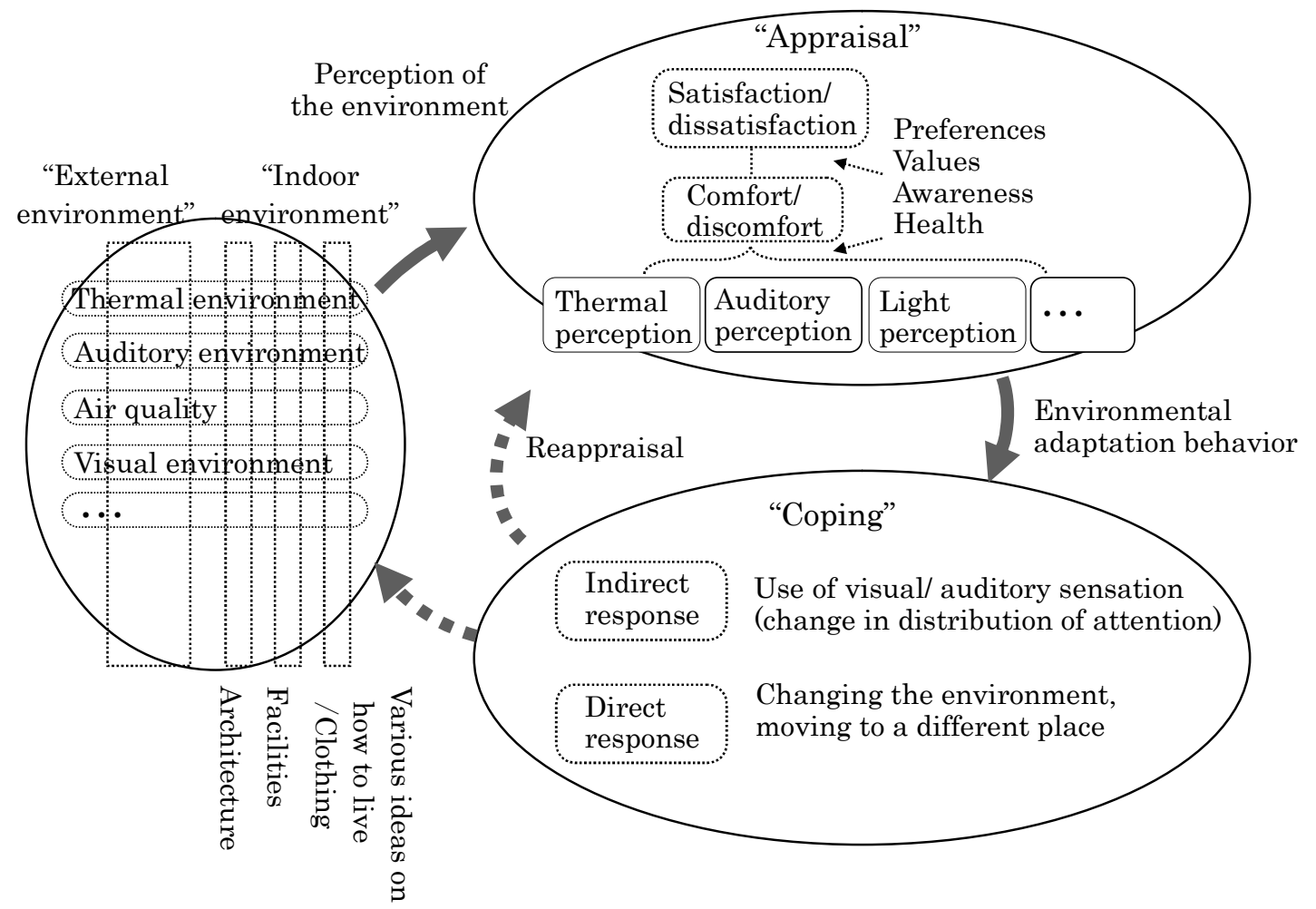

Figure 1. Perceptual appraisal and coping model (Fukusaka et al., 2013) 
behaviors. The survey was conducted in the Nijojo-kita area of Kamigyo-ku, which is a densely populated area (consisting of semi-industrial and neighborhood commercial areas) in the center of Kyoto. This location was selected because it is a residential area in which old town houses, where traditional customs were assumed to be observed, are interspersed with recently rebuilt houses. The questionnaire was posted to 600 detached and row houses in the area and returned by mail. Residents of collective housing were excluded from the study. A total of 245 questionnaires were returned, for a response rate of $40.8 \%$. The questionnaire was distributed in late September 2010 and collected in early October 2010. The outline of the questionnaire is shown in Table 1. The questionnaire probed frequency of air-conditioner use (the number of days used in a week), timing of air-conditioner use (the time of day air-conditioner use begins and ends in the living room during the summer of that year), and other cooling behaviors. In addition to Matsubara et al. (1999), the following cooling behaviors at home that incorporate visual, auditory, and other sensation were investigated: (1) sprinkling water, (2) bamboo blinds (for external use), (3) cooling off outside in the evening, (4) changing rugs and covers (wicker rugs and sofa covers) according to the season (hereafter rugs), (5) wind chimes, (6) rattan furniture and bamboo slides (for indoors, hereafter furniture), (7) cool-colored interior (i.e., curtains and objects), (8) music with cooling effects, (9) incense and scents with cooling effects (hereafter scents with cooling effects), and (10) other. Some of these behaviors comprise thermal factors that influence perceived temperature, while others comprise psychological factors that do not influence perceived temperature. Some comprise both. We assume that residents are not aware of the distinction and therefore behaviors are assumed to consist of both elements. For each behavior, questions were asked about engagement ("currently engaged," "was engaged but no longer," and "not engaged") and reasons for this behavior. These are summarized in Table 2. Respondents were asked to respond to the questionnaire bearing the hottest period of summer in mind. The average temperature of August in the year the questionnaire was administered was $30.1^{\circ} \mathrm{C}$, which exceeded the average temperature by $2.3^{\circ} \mathrm{C}$ (range: $26.3-35.2^{\circ} \mathrm{C}$ ). It was also the hottest period up to that point that year.

We calculated cooling load according to the duration of air-conditioner use (the time of year air-conditioner use begins and ends) as reported in responses to the questionnaire. In terms of presumed family composition, the daily routine of residents, the timing of airconditioner use, the timing of light- and heat-generating device use, and the conditions for "the project to develop an autonomous and circulatory house" (IBEC, 2009) are used. The calculation of cooling load was conducted using SMASH for Windows Ver. 2.11J, which performs dynamic heat load calculation of multiple rooms using a heat circuit network model. The standard model for a residential house by the Architectural Institute of Japan (total floor area of $125.87 \mathrm{~m}^{2}$, two-story) was used as the model house for calculation. Meteorological data were taken from the AMEDAS expanded data (local area: Osaka) and incorporated into the house data for SMASH for Windows.

\section{Results and Discussion}

\subsection{Respondents and their houses}

The gender composition of respondents was $38.3 \%$ men (85) and $61.7 \%$ women (137), excluding non-responses (Table 3). The majority of respondents were in their $60 \mathrm{~s}$ at $26.0 \%$ (57), followed by $23.7 \%$ (52) in their 50s, 19.2\% (42) in their 70s, 13.7\% (30) in their $40 \mathrm{~s}, 9.1 \%$ (20) in their $80 \mathrm{~s}, 5.5 \%$ (12) in their $30 \mathrm{~s}$, $1.8 \%$ (4) in their $20 \mathrm{~s}$, and $0.9 \%$ (2) in their $90 \mathrm{~s}$ (Table 4). With regard to the type of house (Table 5), 84.8\% (195) were wooden, and 50.4\% (114) measure less than $100 \mathrm{~m}^{2}$ in terms of floor space (Table 6). In total, $16.4 \%$ (28) of houses were built less than 10 years ago, $24.6 \%$ (42) between 10 and 19 years ago, 18.7\% (32) between 20 and 29 years ago, $14.0 \%$ (24) between 30 and 39 years ago, 11.9\% (19) between 40 and 49 years ago, $2.9 \%$ (5) between 50 and 59 years ago, 2.3\% (4) between 60 and 69 years ago, 1.8\% (3) between 70 and

Table 1. Outline of the questionnaire

\begin{tabular}{ll}
\hline \multicolumn{1}{c}{ Categories } & \multicolumn{1}{c}{ Items in the questionnaire } \\
\hline $\begin{array}{l}\text { The use of cooling devices in } \\
\text { the living room }\end{array}$ & $\begin{array}{l}\text { Are air-conditioners and/or electric fans used } \\
\text { Frequency of air-conditioner use (the number of days used in a week) } \\
\text { Timing of air-conditioner use (the time of day air-conditioner use begins and ends) } \\
\text { Duration of air-conditioner use (the time of year air-conditioner use begins and ends) }\end{array}$ \\
& $\begin{array}{l}\text { (1) Sprinkling water (watering), (2) Bamboo blinds (for external use), (3) Cooling off outside in the } \\
\text { evening, (4) Changing rugs and covers (wicker rugs and sofa covers) according to season, (5) Wind } \\
\text { chimes, (6) Rattan furniture and bamboo slide (for indoors), (7) Cool-colored interior (curtains and } \\
\text { objects), (8) Music with cooling effects, (9) Incense and scents with cooling effects, and (10) Other } \\
\text { Engagement with and reasons for each behavior }\end{array}$
\end{tabular}

The respondent's attributes House type, number of years since it was built, length of residency at address, age, gender, and family composition of the respondent 
Table 2. Reason for engagement of cooling behaviors

\begin{tabular}{|c|c|}
\hline & Currently engaged \\
\hline $\begin{array}{l}\text { (1) Sprinkling water } \\
\text { (watering) }\end{array}$ & $\begin{array}{l}\text { 1.To lower the temperature } \\
\text { 2.To create the perception of coolness } \\
\text { 3.To suppress dust } \\
\text { 4.In addition to watering the plants } \\
\text { 5.Habitual } \\
\text { 6.Others }\end{array}$ \\
\hline $\begin{array}{l}\text { (2) Bamboo blinds (for } \\
\text { external use) }\end{array}$ & $\begin{array}{l}\text { 1.To shut out direct sunlight } \\
\text { 2.To interrupt other persons' looking } \\
\text { 3.To create the perception of coolness } \\
\text { 4.Suitable for the season } \\
\text { 5.Habitual } \\
\text { 6.Others }\end{array}$ \\
\hline $\begin{array}{l}\text { (3) Cooling off outside } \\
\text { in the evening }\end{array}$ & $\begin{array}{l}\text { 1.To create the perception of coolness } \\
\text { 2.To feel closer to nature } \\
\text { 3.To converse with neighbors } \\
\text { 4. Relaxing } \\
\text { 5.Habitual } \\
\text { 6.Others }\end{array}$ \\
\hline $\begin{array}{l}\text { (4) Changing rugs and } \\
\text { covers (wicker rugs } \\
\text { and sofa covers) } \\
\text { according to season }\end{array}$ & $\begin{array}{l}\text { 1.Not sticky } \\
\text { 2. To create the perception of coolness } \\
\text { 3. Suitable for the season } \\
\text { 4.Habitual } \\
\text { 5. Others }\end{array}$ \\
\hline (5) Wind chimes & $\begin{array}{l}\text { 1. Can feel the wind is blowing } \\
\text { 2. To create the perception of coolness } \\
\text { 3. Auditory pleasant } \\
\text { 4. Suitable for the season } \\
\text { 5.Habitual } \\
\text { 6.Others }\end{array}$ \\
\hline $\begin{array}{l}\text { (6) Rattan furniture and } \\
\text { bamboo slide (for } \\
\text { indoors) }\end{array}$ & $\begin{array}{l}\text { 1. To improve air circulation } \\
\text { 2. To create the perception of coolness } \\
\text { 3. Suitable for the season } \\
\text { 4.Habitual } \\
\text { 5. Others }\end{array}$ \\
\hline $\begin{array}{l}\text { (7) Cool-colored } \\
\text { interior (curtains } \\
\text { and objects) }\end{array}$ & $\begin{array}{l}\text { 1.To create the perception of coolness } \\
\text { 2.Habitual } \\
\text { 3. Suitable for the season } \\
\text { 4.Others }\end{array}$ \\
\hline $\begin{array}{l}\text { (8) Music with cooling } \\
\text { effects }\end{array}$ & $\begin{array}{l}\text { 1.To create the perception of coolness } \\
\text { 2.Relaxing } \\
\text { 3. To change the mood } \\
\text { 4. Likes the music } \\
\text { 5.Suitable for the season } \\
\text { 6.Habitual } \\
\text { 7.Others }\end{array}$ \\
\hline $\begin{array}{l}\text { (9) Incense and scents } \\
\text { with cooling effects }\end{array}$ & $\begin{array}{l}\text { 1. To create the perception of coolness } \\
\text { 2.Relaxing } \\
\text { 3. To change the mood } \\
\text { 4.Like the scent } \\
\text { 5. Suitable for the season } \\
\text { 6.Habitual } \\
\text { 7.Others }\end{array}$ \\
\hline
\end{tabular}

Table 3. Respondents' gender

\begin{tabular}{ccc}
\hline Gender & Number & Percentage \\
\hline Male & 85 & $38.3 \%$ \\
Female & 137 & $61.7 \%$ \\
\hline
\end{tabular}

Table 4. Respondents' age

\begin{tabular}{ccc}
\hline Age & Number & Percentage \\
\hline $20 \mathrm{~s}$ & 4 & $1.8 \%$ \\
$30 \mathrm{~s}$ & 12 & $5.5 \%$ \\
$40 \mathrm{~s}$ & 30 & $13.7 \%$ \\
$50 \mathrm{~s}$ & 52 & $23.7 \%$ \\
$60 \mathrm{~s}$ & 57 & $26.0 \%$ \\
$70 \mathrm{~s}$ & 42 & $19.2 \%$ \\
$80 \mathrm{~s}$ & 20 & $9.1 \%$ \\
$90 \mathrm{~s}$ & 2 & $0.9 \%$ \\
\hline
\end{tabular}

Table 5. The type of house

\begin{tabular}{ccc}
\hline Type & Number & Percentage \\
\hline Wooden & 195 & $84.8 \%$ \\
Steel framed & 22 & $9.6 \%$ \\
Concrete & 4 & $1.7 \%$ \\
Other & 9 & $3.9 \%$ \\
\hline
\end{tabular}

Table 6. Floor area

\begin{tabular}{lcc}
\hline \multicolumn{1}{c}{ Floor area } & Number & Percentage \\
\hline $100 \mathrm{~m}^{2}$ or less & 114 & $50.4 \%$ \\
Between $101 \mathrm{~m}^{2}$ and $150 \mathrm{~m}^{2}$ & 66 & $29.2 \%$ \\
Between $151 \mathrm{~m}^{2}$ and $200 \mathrm{~m}^{2}$ & 26 & $11.5 \%$ \\
$201 \mathrm{~m}^{2}$ or more & 20 & $8.8 \%$ \\
\hline
\end{tabular}

Table 7. Number of years since the house was built

\begin{tabular}{lcc}
\hline \multicolumn{1}{c}{ No. of Years } & Number & Percentage \\
\hline Less than 10 years & 28 & $16.4 \%$ \\
Between 10 and 19 years & 42 & $24.6 \%$ \\
Between 20 and 29 years & 32 & $18.7 \%$ \\
Between 30 and 39 years & 24 & $14.0 \%$ \\
Between 40 and 49 years & 19 & $11.1 \%$ \\
Between 50 and 59 years & 5 & $2.9 \%$ \\
Between 60 and 69 years & 4 & $2.3 \%$ \\
Between 70 and 79 years & 3 & $1.8 \%$ \\
Between 80 and 89 years & 10 & $5.8 \%$ \\
90 years or more & 4 & $2.3 \%$ \\
\hline
\end{tabular}

79 years ago, 5.8\% (10) between 80 and 89 years ago, and $2.3 \%$ (4) 90 years ago and more (Table 7). Houses built a long time ago and those rebuilt less than 30 years ago account for $54.0 \%$ of the houses surveyed. In addition, a significant positive correlation between the number of years since the house was built and respondents' age was evident $(\mathrm{r}=0.40, \mathrm{p}<0.01)$.

\subsection{Use of air-conditioners and electric fans}

Figure 2 shows the use of air-conditioners and electric fans in the living room. Of the respondents, $23.2 \%$ used air-conditioners only, although the majority used both air-conditioners and electric fans $(70.2 \%)$. A total of $16.0 \%$ used electric fans only. With regard to frequency of air-conditioner use (Figure 3), the majority used air-conditioners for 6 or more days a week (81.8\%), 13.0\% used them 4 to 5 days a week, $4.3 \%$ used them 2 to 3 days a week, and $0.9 \%$ used them less than 1 day a week.

\subsection{Cooling behaviors}

Figure 4 shows various cooling behaviors other than using air-conditioners and electric fans. Among "currently engaged" behaviors, the most popular was the use of rugs, at $57.5 \%$ (130), followed by sprinkling water at $46.4 \%$ (109), bamboo blinds at $40.9 \%$ (96), and a cool-colored interior at 30.5\% (68). The least popular was cooling off outside in the evening at $2.1 \%$ (5). The most popular "was engaged but no longer" behaviors were cooling off outside in the evening, at 


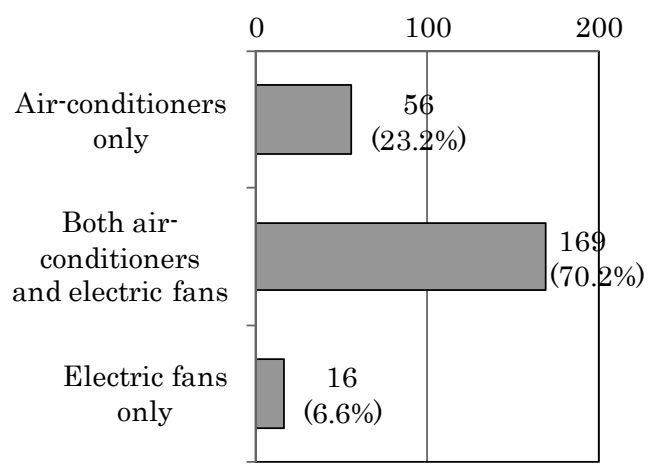

Figure 2. Use of air-conditioners and electric fans $(n=241)$

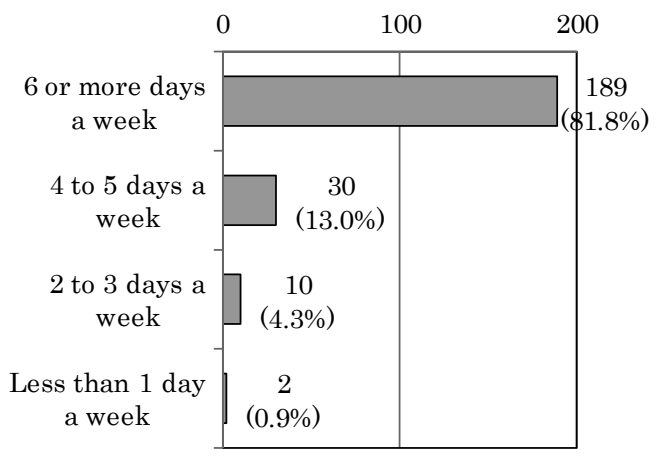

Figure 3. The frequency of air-conditioning use $(n=231)$

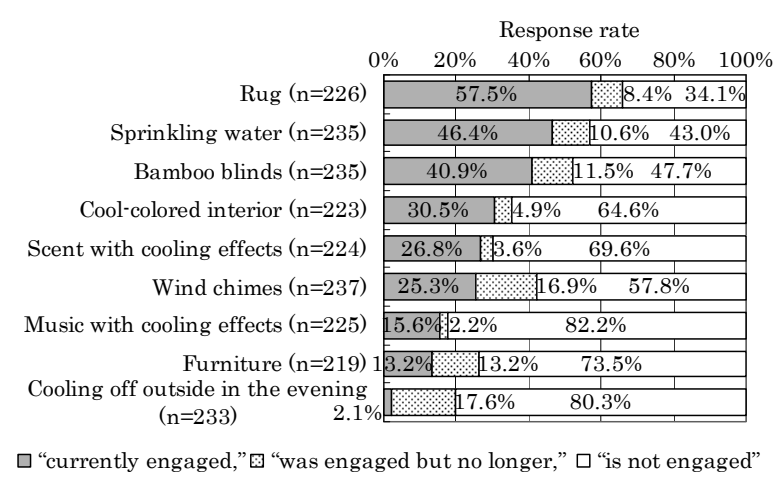

Figure 4. Cooling behaviors

$17.6 \%$ (41), followed by wind chimes at $16.9 \%$ (40), furniture at $13.2 \%$ (29), and bamboo blinds at $11.5 \%$ (27). On the other hand, "not engaged" behaviors, in descending order, were music with cooling effects at $82.2 \%$ (185), cooling off outside in the evening at $80.3 \%$ (187), furniture at $73.5 \%$ (161), and scent with cooling effects at 69.6\% (156). Matsubara et al. (2009) conducted a longitudinal survey of traditional environment adjustment behaviors during summer months, which indicated that the use of bamboo blinds, sprinkling water, and cooling off outside in the evening is decreasing. As such, our survey, although conducted at a different location, has revealed an even lower rate of engagement in these behaviors.

Figures 5 to 13 show the reasons for each behavior. Reasons such as "suitable for the season" and "feeling cool" were chosen frequently for rugs (Figure 5), a cool-colored interior (Figure 8), and furniture (Figure 12), indicating that, through these behaviors, respondents created a sense of matching the season and coolness through stimulation of the visual and tactile sensation. Respondents sprinkled water (Figure 6) because of the behaviors "in addition to watering the plants" and "lowering the temperature," which suggest habitual engagement to lower perceived temperature. For bamboo blinds (Figure 7), many respondents chose "to shut out direct sunlight" and "to interrupt other persons' looking," suggesting that these behaviors reduced exposure to direct sunlight and interrupt other persons' looking. Scents with cooling effects (Figure 9), wind chimes (Figure 10), and music with cooling effects (Figure 11) were selected because they were

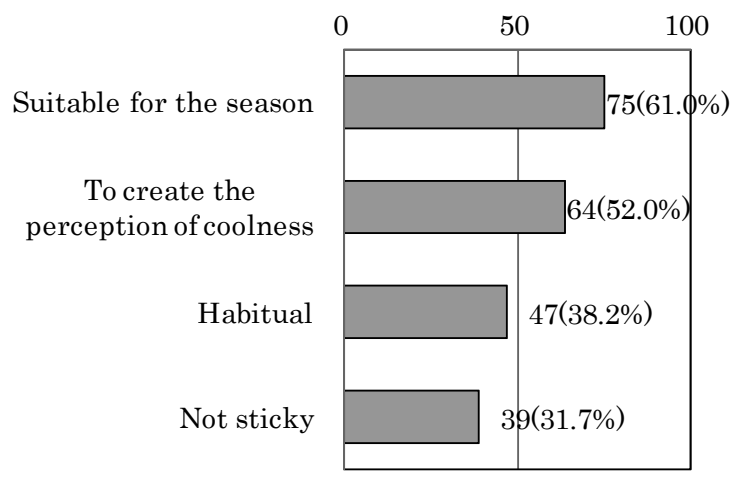

Figure 5. Reasons for using rugs $(\mathrm{n}=123)$

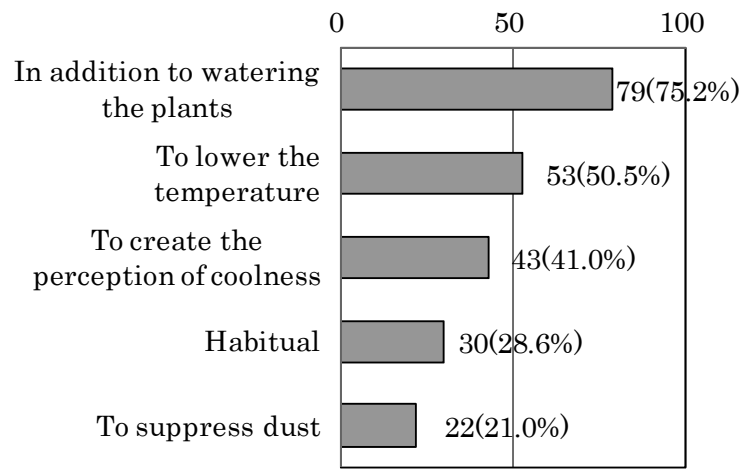

Figure 6. Reasons for sprinkling water $(\mathrm{n}=105)$

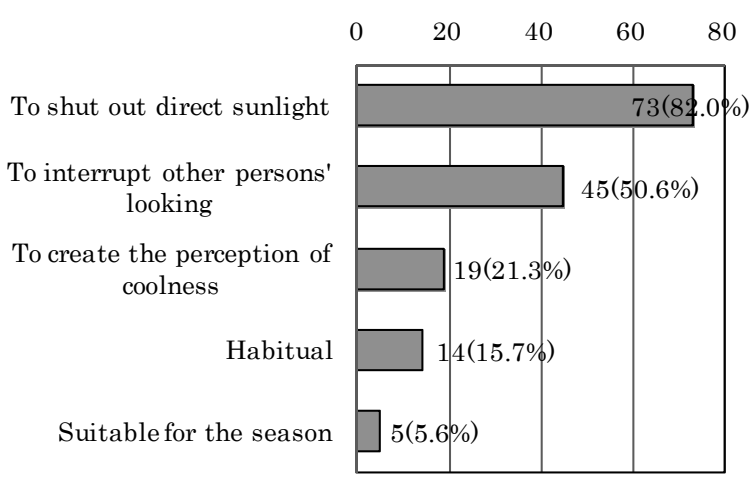

Figure 7. Reasons for using bamboo blinds $(n=89)$ 
"relaxing" and "auditory pleasant" and respondents "like the scent," suggesting that respondents pursued healing and comfort regardless of perceived temperature. Cooling off outside in the evening (Figure 13) was selected behavior for "creating the perception of coolness" as in the cases of rugs, a cool-colored interior, and furniture, although actual engagement was low.

Table 8 shows the duration of air-conditioners use, the number of years since the house was built, and the age of respondents, all of which were significantly correlated with cooling behaviors and respondents' attributes. The Pearson's coefficients between each behavior were also indicated. The correlation between sprinkling water and bamboo blinds was statistically

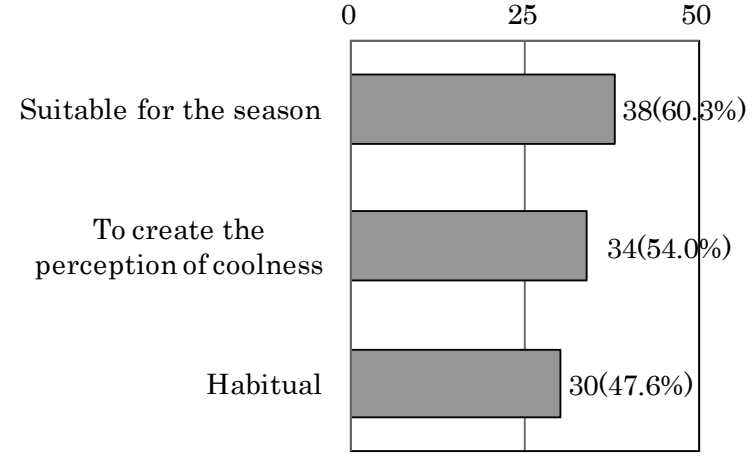

Figure 8. Reasons for using a cool-colored interior $(n=63)$

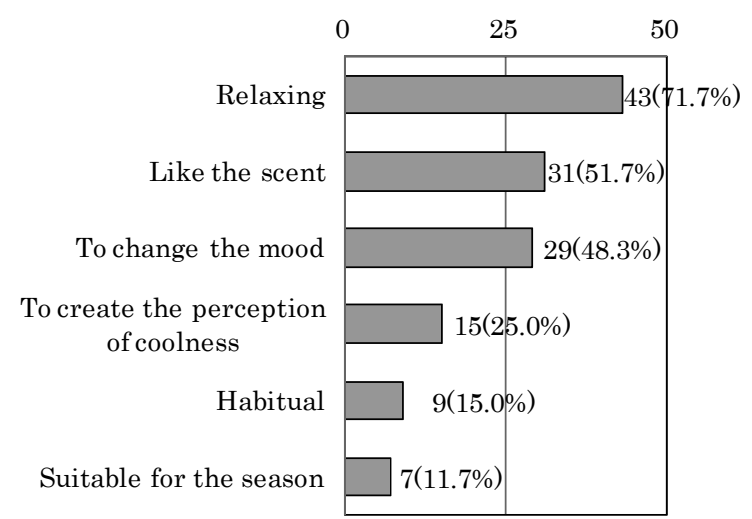

Figure 9. Reasons for using scents with cooling effects $(n=60)$

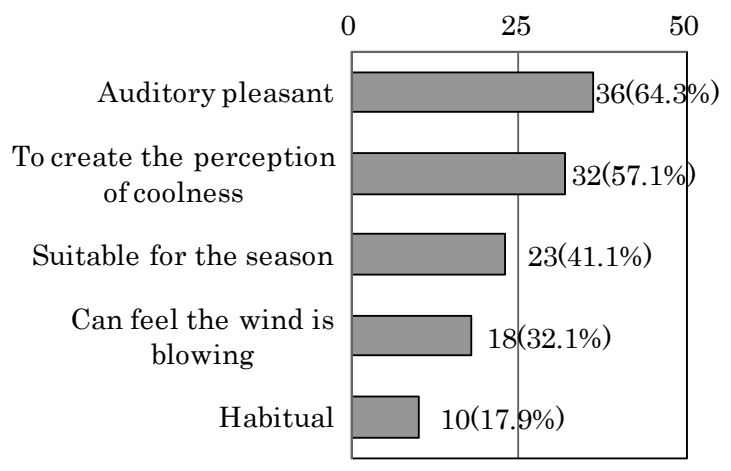

Figure 10. Reasons for using wind chimes $(\mathrm{n}=56)$ significant $(\mathrm{r}=0.25, \mathrm{p}<0.01)$ and, because these behaviors were selected to "lower the perceived temperature" or "to shut out direct sunlight," they were engaged in simultaneously to lower the temperature. Furthermore, the correlation was statistically significant between rugs and furniture $(r=0.25, \mathrm{p}<0.01)$ and a cool-colored interior $(\mathrm{r}=0.27, \mathrm{p}<0.01)$, as well as between furniture and a cool-colored interior $(r=0.27$, $\mathrm{p}<0.01)$. As these behaviors were "suitable for the season," "create the perception of coolness," and "improve air circulation," it can be deduced that by changing clothing according to the season, respondents expect lower temperatures and psychological cooling effects through manipulation of the visual sensation. On the other hand, the statistically significant correlations between scent with cooling effects and wind chimes $(\mathrm{r}=0.23, \mathrm{p}<0.01)$, a cool-colored interior $(\mathrm{r}=$

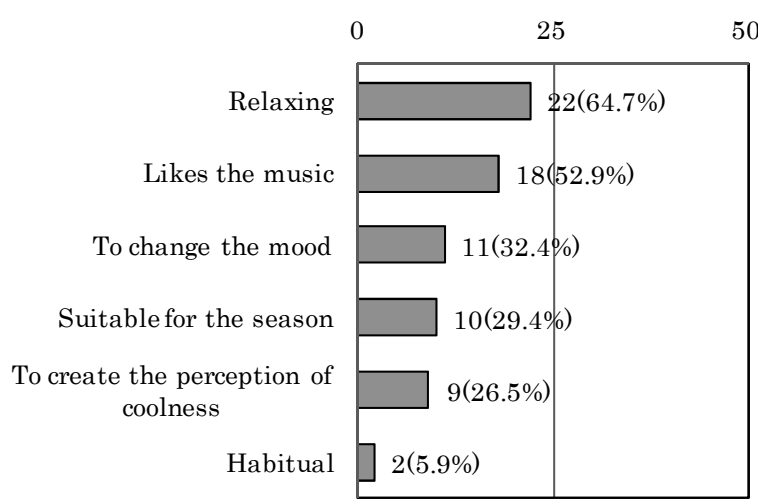

Figure 11. Reasons for using music with cooling effects $(\mathrm{n}=34)$

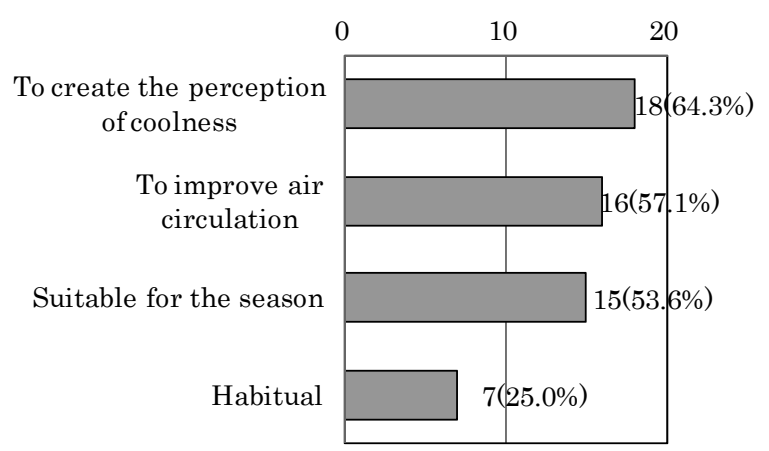

Figure 12. Reasons for using furniture $(n=28)$

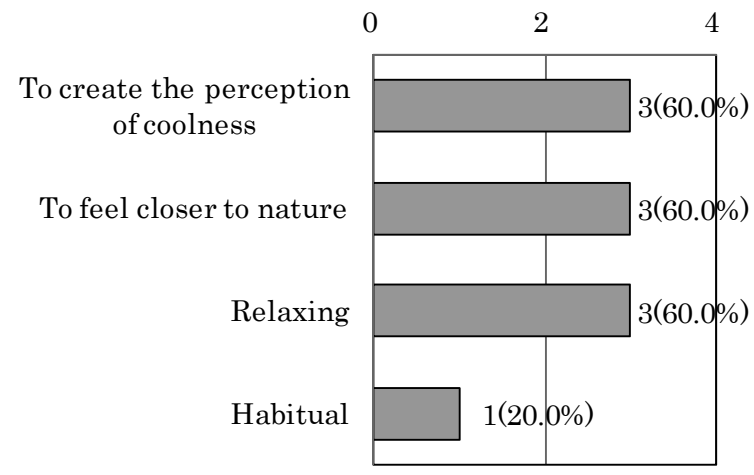

Figure 13. Reasons for cooling off outside in the evening $(n=5)$ 
$0.24, \mathrm{p}<0.01)$, and music with cooling effects $(\mathrm{r}=$ $0.33, \mathrm{p}<0.01$ ), which were behaviors chosen for reasons of "relaxing," "liking the scent," "auditory pleasant," and "to change the mood," means that these behaviors were not engaged in for their thermal effects but rather to obtain psychological comfort and healing. The correlation was statistically significant between the number of years since the house was built and furniture $(\mathrm{r}=0.23, \mathrm{p}<0.01)$ and bamboo blinds $(\mathrm{r}=0.18, \mathrm{p}<$ $0.05)$, suggesting that furniture and bamboo blinds were used more often in older houses. The number of years since the house was built was also correlated with the respondent's age $(r=0.40, p<0.01)$. In terms of the relationship between cooling behaviors and the duration of air-conditioners use, a negative correlation, except for cooling off outside in the evening and scent with cooling effects, was evident. Also evident was a statistically significant correlation with bamboo blinds $(\mathrm{r}=-0.17, \mathrm{p}<0.05)$ and a cool-colored interior $(\mathrm{r}=$ $-0.14, p<0.05)$. The average actual engagement with cooling behaviors was 2.4 , and there was a significant negative correlation with the duration of air-conditioners use $(r=-0.13, p<0.05)$. The more residents engaged in cooling behaviors, the shorter the duration of air-conditioners used.

\subsection{Estimation of cooling load by thermal load simulation}

Section 4.3 has shown that the reasons residents engage in cooling behaviors include, in addition to lowering perceived temperature, to feel a match to the season, to create the perception of coolness, to relax, and to improve a sense of comfort and healing. It has also been revealed that these behaviors have a negative correlation with the duration of air-conditioner use. We have therefore attempted to calculate the influence of cooling behaviors on cooling load. The estimated cooling load is based on data of the duration of air-conditioner use obtained from the questionnaire. Since this is based on reports by residents themselves, it is considered to be meaningful data that shows the influence of cooling behavior on cooling load.

Figure 14 shows the seasonal variation of the rate of air-conditioner use in the living room. The rate of air-conditioner use from early July to mid-September is high at more than $50 \%$. It is useful to recall that "bamboo blinds" and "a cool-colored interior" have statistically significant negative correlations with the

Table 8. Correlation coefficients for cooling behaviors and duration of air-conditioner use

\begin{tabular}{|c|c|c|c|c|c|c|c|c|c|c|c|}
\hline & $(1)$ & $(2)$ & (3) & $(4)$ & $(5)$ & $(6)$ & $(7)$ & $(8)$ & (9) & $(10)$ & $(11)$ \\
\hline \multicolumn{12}{|l|}{ (1) Sprinkling water } \\
\hline (2) Bamboo blinds & $0.25^{* *}$ & & & & & & & & & & \\
\hline (3) Cooling off outside in the evening & 0.10 & 0.06 & & & & & & & & & \\
\hline (4) Rugs & 0.10 & 0.02 & 0.01 & & & & & & & & \\
\hline (5) Wind chimes & 0.12 & 0.00 & -0.02 & 0.07 & & & & & & & \\
\hline (6) Furniture & -0.05 & 0.12 & -0.05 & $0.25^{* *}$ & 0.09 & & & & & & \\
\hline (7) A cool-colored interior & 0.06 & $0.15^{*}$ & $0.16^{*}$ & $0.27 * *$ & 0.01 & $0.27 * *$ & & & & & \\
\hline (8) Music with cooling effects & $0.13^{*}$ & -0.01 & 0.02 & 0.11 & $0.14 *$ & 0.04 & $0.15^{*}$ & & & & \\
\hline (9) Scent with cooling effects & 0.10 & -0.01 & 0.05 & 0.08 & $0.23 * *$ & -0.02 & $0.24 * *$ & $0.33 * *$ & & & \\
\hline (10) The duration of air-conditioning use & -0.09 & $-0.17 *$ & 0.05 & -0.02 & -0.07 & -0.11 & $-0.14 *$ & -0.02 & 0.03 & & \\
\hline (11) Number of years since the house was built & 0.08 & $0.18^{*}$ & 0.03 & 0.09 & 0.12 & $0.23 * *$ & 0.13 & 0.14 & 0.03 & -0.08 & \\
\hline (12) Respondent's age & 0.07 & $0.14 *$ & -0.12 & -0.01 & 0.03 & $0.14 *$ & 0.11 & 0.10 & -0.07 & -0.03 & $0.40 * *$ \\
\hline
\end{tabular}

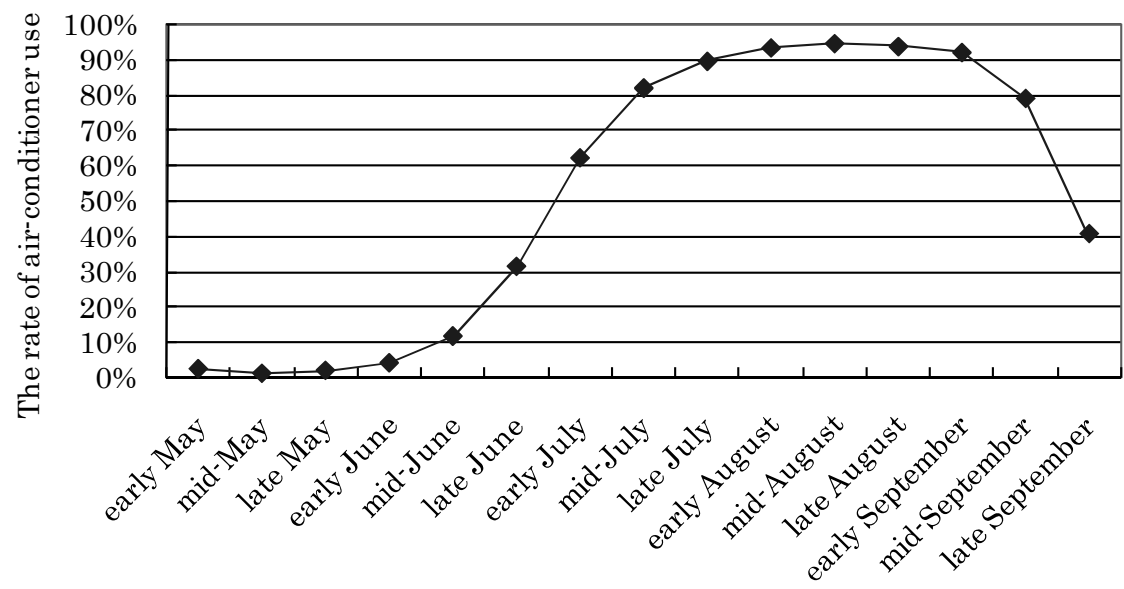

Figure 14. The rate of air-conditioning use in the living room 
duration of air-conditioner use and the incidence of cooling behaviors. We calculated the average duration of air-conditioner use among those using bamboo blinds and a cool-colored interior (Table 9). The average duration of air-conditioner use is 81.7 days among those "who do not use bamboo blinds or a coolcolored interior" (named NN), 81.6 days among those "who do not use bamboo blinds but use a cool-colored interior" (named NI), 76.9 days among those "who use bamboo blinds but do not use a cool-colored interior" (named BN), and 64.5 days among those "who use both bamboo blinds and a cool-colored interior" (named BI).

The start and end dates of air-conditioner use are set based on the average duration of air-conditioner use for each group, following which cooling load is calculated. Because it is presumed that the insulation performance of the houses varied in accordance with the year each house was built (Table 7), calculations were performed using both of model houses that the model house meeting energy saving standard of next-generation which was the most excellent in insulation performance, and the model house which had not insulated that resulted in cooling load reduction. These assumptions are indicated in Table 10.

Table 11 shows the results of the cooling load calculation for each group. The cooling load of the next generation energy-saving specification house is $12,026.9 \mathrm{MJ}$ for the NN and NI groups, $11,862.0 \mathrm{MJ}$ for the $\mathrm{BN}$ group, and $10,760.2 \mathrm{MJ}$ for the $\mathrm{BI}$ group. The cooling load for the BN group is about $1 \%$ lower than the NN group, while that of the BI group is about $10 \%$ lower. This is similar for the non-insulated specifications. In short, the use of bamboo blinds or a cool-colored interior makes it possible to survive in a very hot environment with a shorter duration of air-conditioner use, by realizing lower perceived temperatures via creating the perception of coolness and matching the conditions to the season through manipulation of the visual, auditory, and other sensation.

Table 12 shows the differences in cooling load according to set cooling temperature. As it was assumed that thermal discomfort was eased by the psychological

Table 9. Duration of air-conditioning use according to behavior

\begin{tabular}{cccccc}
\hline Group & Bamboo blinds & $\begin{array}{c}\text { A cool-colored } \\
\text { interior }\end{array}$ & Number & $\begin{array}{c}\text { Average duration of air- } \\
\text { conditioning use (days) }\end{array}$ & Set cooling period \\
\hline NN & Not engaged & Not engaged & 99 & 81.7 & $7 / 2 \sim 9 / 21$ \\
\hline NI & Not engaged & engaged & 31 & 81.6 & $7 / 2 \sim 9 / 21$ \\
\hline BN & engaged & Not engaged & 54 & 76.9 & $7 / 4 \sim 9 / 19$ \\
\hline BI & engaged & engaged & 31 & 64.5 & $7 / 11 \sim 9 / 12$ \\
\hline
\end{tabular}

Table 10. Major specifications of the model house for calculation

\begin{tabular}{cccc}
\hline \multirow{2}{*}{$\begin{array}{c}\text { Major } \\
\text { insulation }\end{array}$} & Outer walls & $\begin{array}{c}\text { Next generation energy- } \\
\text { saving specification }\end{array}$ & No insulation \\
\cline { 2 - 4 } & 2F Ceiling & GW(16K) t100 & - \\
\cline { 2 - 4 } & Floor of the first floor & GW(16K) t100 & - \\
\cline { 2 - 4 } & Windows & Double glazing & Single glazing \\
\hline \multirow{2}{*}{$\begin{array}{c}\text { The frequency of change of air } \\
\text { (Frequency/hour) }\end{array}$} & 0.5 & 2.0 \\
\hline
\end{tabular}

※GW: Glass Wool; $10 \mathrm{~K}: 10 \mathrm{~kg} / \mathrm{m}^{3} ; 16 \mathrm{~K}: 16 \mathrm{~kg} / \mathrm{m}^{3}$; t: thickness (mm)

Table 11. Cooling load according to behavior

\begin{tabular}{|c|c|c|c|c|c|c|}
\hline \multirow[t]{2}{*}{ Group } & \multirow[t]{2}{*}{ Bamboo blinds } & \multirow[t]{2}{*}{$\begin{array}{l}\text { A cool-colored } \\
\text { interior }\end{array}$} & \multicolumn{2}{|c|}{$\begin{array}{l}\text { Next generation energy-saving } \\
\text { specification }\end{array}$} & \multicolumn{2}{|c|}{ No insulation } \\
\hline & & & Cooling load (MJ) & Proportion & Cooling load (MJ) & Proportion \\
\hline $\mathrm{NN}$ & Not engaged & Not engaged & $12,026.9$ & - & $17,511.5$ & - \\
\hline NI & Not engaged & Engaged & $12,026.9$ & $100.0 \%$ & $17,511.5$ & $100.0 \%$ \\
\hline $\mathrm{BN}$ & Engaged & Not engaged & $11,862.0$ & $98.6 \%$ & $17,368.3$ & $99.2 \%$ \\
\hline BI & Engaged & Engaged & $10,760.2$ & $89.5 \%$ & $16,199.2$ & $92.5 \%$ \\
\hline
\end{tabular}

Table 12. Cooling load according to set cooling temperature

\begin{tabular}{|c|c|c|c|c|c|c|c|}
\hline \multirow[t]{2}{*}{ Group } & \multirow[t]{2}{*}{ Bamboo blinds } & \multirow[t]{2}{*}{$\begin{array}{l}\text { A cool-colored } \\
\text { interior }\end{array}$} & \multirow[t]{2}{*}{$\begin{array}{l}\text { Set cooling } \\
\text { temperature }\left({ }^{\circ} \mathrm{C}\right)\end{array}$} & \multicolumn{2}{|c|}{$\begin{array}{l}\text { Next generation energy-saving } \\
\text { specification }\end{array}$} & \multicolumn{2}{|c|}{ No insulation } \\
\hline & & & & Cooling load (MJ) & Proportion & Cooling load (MJ) & Proportion \\
\hline $\mathrm{NN}$ & Not engaged & Not engaged & $27[28]$ & $12,026.9$ & - & $17,511.5$ & - \\
\hline BI & Engaged & Engaged & $27[28]$ & $10,760.2$ & $89.5 \%$ & $16,199.2$ & $92.5 \%$ \\
\hline $\mathrm{BI}$ & Engaged & Engaged & 28 [29] & $9,967.8$ & $82.9 \%$ & $14,750.0$ & $84.2 \%$ \\
\hline
\end{tabular}


effects of visual and auditory sensation, we calculated that the reduction effect of the cooling load would enable the set cooling temperature to be raised by $1{ }^{\circ} \mathrm{C}$. When the set cooling temperature in the $\mathrm{BI}$ group is raised $1{ }^{\circ} \mathrm{C}$ from $27^{\circ} \mathrm{C}\left(28^{\circ} \mathrm{C}\right.$ during bedtime), the cooling load becomes 9,967.8MJ, which represents a $17 \%$ reduction in cooling load (a next generation energy-saving specification). It also reduces cooling load in a non-insulated house.

The reduction in cooling load achieved by using bamboo blinds and a cool-colored interior has been calculated based on data collected from the survey on duration of air-conditioners use. In the BI group, the duration of air-conditioner use is shorter because these behaviors produce the perception of coolness. It is therefore assumed that they are more tolerant of a hot environment. For this reason, we conducted a simulation by increasing the set temperature by $1{ }^{\circ} \mathrm{C}$. The spread of air-conditioners eases the creation of a pleasant thermal environment. However, residents seem to actively use bamboo blinds and a cool-colored interior to shut out direct sunlight, and to create the perception of coolness and a feeling of seasonal match through manipulation of the visual, auditory, and other sensation. By doing so, residents obtain psychological comfort and healing and a sense of satisfaction, which helps them survive hot environments. This suggests that tolerance for hot environments can increase through cooling behaviors, which in turn suggests the possibility of reducing cooling load.

\section{Conclusions}

The preceding examination produced the following insights:

1) The study has shown that, in addition to using an airconditioner, many residents were engaged in daily behaviors such as using rugs, sprinkling water, using bamboo blinds, and a cool-colored interior. Many of these behaviors showed a statistically significant negative correlation to the duration of air-conditioners use.

2) Among cooling behaviors, reasons for sprinkling water and using bamboo blinds include "lowering the temperature to feel cool" and "to shut out direct sunlight," respectively. These behaviors were primarily aimed at producing thermal effects. When using rugs, a cool-colored interior, scents with cooling effects, wind chimes, and music with cooling effects, the main aim was to obtain non-thermal effects through achieving comfort and healing by "creating the perception of coolness" or "feeling a seasonal match."

3) A simulation of cooling load using the duration of air-conditioners use in four groups categorized according to the combination of the use or non-use of bamboo blinds and a cool-colored interior, was conducted. The group using both bamboo blinds and a cool-colored interior (BI) reduced cooling load by about $10 \%$ compared to the group using neither $(\mathrm{NN})$. The reason is attributed to improved overall satisfaction brought about by cooling behaviors that employ visual and auditory sensation. It has been suggested that the use of visual and auditory sensation could expand the range of tolerated temperatures and reduce cooling load.

When there were no air-conditioners, human beings adapted through environment adjustment techniques in architecture such as ensuring air circulation, shutting out direct sunlight and by residents' active environment adjustment behavior. This has shaped the locality, custom, and culture of cooling behavior. In addition, living a normal life used to mean using and training the sensation, but it is feared that the opportunity to use our sensation in modern life is diminishing (Fukushima, 2012). On one hand, we can now easily create a pleasant environment using air-conditioners, while on the other, there are suggestions that our thermal adaptation ability is declining because we live in a constantly pleasant environment. This is evident in the harm caused by too much air-conditioning and the decline in sweat gland function (Ogawa, 1992). Creating a pleasant air-conditioned environment is essential for avoiding harm to health (heat stroke) and significant reductions in productivity and economic activity, but the re-examination of the meaning of a pleasant environment and traditional wisdom is now being sought (Matsubara et al., 1992). In other words, a pleasant environment is not solely dependent on airconditioning, but can be achieved by obtaining psychological satisfaction through active engagement in cooling behaviors to achieve a sense of coolness, seasonal match, comfort, and healing. It is also possible to accept a degree of heat by relying not only on thermal pleasantness but also on the improvement of overall satisfaction resulting from cooling behaviors, which use our sensation. The clues for this can be found in the traditional wisdom integrated into culture by our ancestors' efforts. We believe that by re-examining these clues and applying them to our lives today, we can develop a new lifestyle characterized by low energy consumption and a higher degree of satisfaction.

Because this study is limited to the survey of Kyoto in summer, future tasks include examining ways of life in other areas with different traditions and cultures and in other seasons.

\section{Acknowledgments}

We would like to thank the respondents who participated in the survey and the students of Kyoto Prefectural University. The study is partly funded by Grant-in-Aid for Scientific Research (Basic Research B, No. 21300270) provided by the Ministry of Education, Culture, Sports, Science and Technology. 


\section{Conflict of Interest}

The authors declare no conflict of interest.

\section{References and Notes}

Agency for Natural Resources and Energy (2013) Annual Energy Report Fiscal Year 2013 [in Japanese] http://www.enecho.meti.go.jp/topics/hakusho/2013/ index.htm (accessed on 23.10.2013).

AIJ (2007) Architectural Design Data Corpus, Environment, Maruzen Publishing, p.6.

Bennett \& Rey (1972) What's so hot about red? Human Factors, 14(2), pp.149-154.

Cabinet Office (2007) White Paper on the National Lifestyle Fiscal Year 2007[in Japanese]

http://www5.cao.go.jp/seikatsu/whitepaper/h19/10 pdf/01 honpen/ (accessed on 23.10.2013).

Seligman, M., Kriss, J. M., Darley, R. H., Fazio, L. J. \& Becker, J. B. (1979) Predicting summer energy consumption from homeowners' attitudes, Journal of Applied Social Psychology, 9, pp.70-90.

Fanger, P. O., Breun, N. O. \& Jerking, E. (1977) Can color and noise influence man's thermal comfort? Ergonomics, 20, pp.11-18.

Folkman, S., \& Lazarus, R. S. (1988) Coping as a mediator of emotion, Journal of Personality and Social Psychology, 54, pp.466-479.

Fukusaka, M., Matsubara, N., Sawashima, T., Yamato, Y., Matsubara, S., Tobita, K., Kurazumi, Y., Gassho, A. \& Shibata, Y. (2013) Field investigation of the behavior for getting the coolness of houses in Kyoto City, Japan, during summer, Japanese Journal of Biometeorology, 50(1), pp.11-21 [in Japanese].

Fukushima, A. (2012) Recovery of sense and vitality (edited by Fukushima, A., Invitation to sense therapy "KANKAKURYOUHOU ENO SYOHTAI", Kazamashobo, p.17) [in Japanese].

Horie, G., Sakurai, Y., Noguchi, T. \& Matsubara, N. (1985) Synthesized evaluation of noise, lighting and thermal conditions in a room, Proceedings of the International Conference of Noise Control Engineering (Krakow), pp.491-496.

Horikoshi, T. (1993) Pleasantness in the context of history (edited by Ohno, H., Horikoshi, T., Kuno, S., Tsuchikawa, T., Matsubara, N., Ito, H: Science of pleasant environment "KAITEKIKANNKYO NO KAGAKU”, Asakura Publishing, pp.5-11).

Humphreys M. A \& Nicol, J. F. (1998) Understanding the adaptive approach to thermal comfort, ASHRAE Transaction, 104(1B), pp.991-1004.

IBEC (2009) Description of the calculation method of energy consumed in the standard of the housing business owner's judgment [in Japanese]

http://ees.ibec.or.jp/documents/img/kaisetsu 200903 all ver2.pdf (accessed on 23.10.2013).

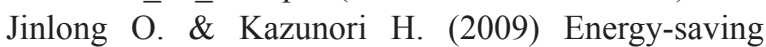 potential by improving occupants' behavior in urban residential sector in Hangzhou City, China, Energy and Buildings, 4, pp.711-720.

Kaneko, M. (1921) Commentary on "Makura no soshi”, First volume "MAKURANOSOUSHI HYOUSYAKU JOHKAN", Meijishoin, pp.3-6. [in Japanese].

Matsubara, N. \& Sawashima, T. (1992) Strategies of environmental control and the traditional houses, Japanese Journal of Biometeorology, 29(2), pp.7782 [in Japanese].

Matsubara, N. \& Sawashima, T. (1993) The actual conditions of practicing traditional methods of environmental control and utilization of air conditioners by the residents of detached houses in Kyoto during summer, Journal of Thermal Biology, 18(5/6), pp.577-582.

Matsubara, N., Ito, K., Gassho, A. \& Kurazumi, Y. (1995) Importance of nonspecific scale and the additive model in the evaluation study of the combined environment, Archives of Complex Environmental Studies, 7, pp.45-54 (Proc. 6th ICCEF94, Toyama Japan, 25-28 September, 121-129, 1994).

Matsubara, N., Sawashima, T., Kurazumi, Y. \& Matsubara, S. (1999) Consciousness and behavior of the people and the indoor climate of houses in Japan, Proc. 1998 International Symposium of Human Biometeorology, pp.29-34.

Matsubara, N., Ito, K., Kurazumi, Y., Gassho, A. \& Nagano, K. (2000) Specific and non-specific evaluation of the combined environment of color and temperature, Journal of Architecture, Planning, and Environmental Engineering, No.535, pp.39-45 [in Japanese].

Matsubara, N., Shimada, R., Kurazumi, Y., Gassho, A. \& Tobita, K. (2007) Effect of the addition of the other factor on the evaluation of the experimental combined environment of thermal visual and acoustic factors, Journal of Environmental Engineering, No.611, pp.83-89 [in Japanese].

Matsubara, N., Miyata, N., Ohyama, T., Sawashima, T., Gassho, A., Yamato, Y., Kurazumi, Y. \& Tobita, K. (2009) To think better about the traditional behaviors as the measures against the climatic change, The Memoirs by Housing Research Foundation, Housing Research Foundation Jusoken, No.36, pp.317-328.

Matsubara, N., Sawashima, T., Yamato, Y., Kurazumi, Y., Tobita, K., Matsubara, S., Gassho, A. \& Fukagawa, K. (2013) Actual condition of the consciousness and the behavior of the residents and the indoor climates of houses in Japan, Clima 2013, 11th REHVA World Congress and 8th International Conference on IAQVEC, Prague, pp.16-19.

Nagano, K., Matsubara, N., Kurazumi, Y., Gassho, A., Ito, K. \& Narumi, D. (1996) Basic considerations on 
evaluation of the combined environment of environmental sound, ambient temperature and illuminance, Journal of Architecture, Planning, and Environmental Engineering, No.490, pp.55-61 [in Japanese].

Ogawa, T. (1992) Comfortable environment vs. optimum environment, Japanese Journal of Biometeorology, 29(2), pp.97-100 [in Japanese].

Ohno, H., Kuno, S., Kida, M. \& Nakahara, N. (1987)

The interactions between thermal sensation and hueheat impression under various thermal conditions, Journal of Architecture, Planning, and Environmental
Engineering, No.374, pp.8-18 [in Japanese].

Saito, M. \& Syukuya, M. (1999) An analysis on the outdoor air movement providing with 'SUZUSISA' sensation, Journal of Architecture, Planning, and Environmental Engineering, No.523, pp.39-44 [in Japanese].

Sakurai, Y., Noguchi, T., Horie, G. \& Matsubara, N. (1990) Quantification of the synthesized evaluation of the combined environment, Energy and Buildings, 14, pp.169-173. 